\title{
Suppression of Substrate Heating in the Sputter-deposition of ITO Films
}

\author{
Kentaro FunATSU, Hiro-omi KATO, and Yoichi HOSHI
}

Faculty of Engineering, Tokyo Polytechnic University (1583 liyama, Atsugi-shi, Kanagawa 243-0297, Japan)

Received November 26, 2003 ; Accepted March 19, 2004

\begin{abstract}
Suppression of substrate heating during film deposition is necessary to realize a high rate deposition of ITO films on plastic film substrate. In a sputter-deposition of the film using a conventional magnetron sputtering system, heating power incident into substrate was measured and mechanisms of the substrate heating were investigated precisely. Most of the incidence power into the substrate is originated in the bombardment of high-energy secondary electrons emitted from the target, and can be reduced to $1 / 9$ by removing the electron bombardment. Compared with the total incidence power to the substrate, the heat of formation of the film was estimated to be below $1 / 50$. This suggests that further reduction of the incidence power into substrate will be possible in the deposition using a conventional magnetron sputtering system.
\end{abstract}

Key Words : Sputtering, Substrate Heating, ITO Film, Plastic Film Substrate

\section{Introduction}

Deposition of the transparent conductive thin films on plastic substrate has been strongly demanded recently, especially in the application of organic LEDs. ${ }^{1,2}$ In order to realize sputter-deposition of the ITO films on plastic substrate, low temperature below $100^{\circ} \mathrm{C}$ and damageless deposition is necessary to obtain the film with low resistivity and excellent surface smoothness. In addition, control of substrate temperature is important to obtain the film with desired microstructure.

It is, however, difficult to suppress the substrate heating when high rate deposition of the film is tried in magnetron sputtering, because the heating power incident to the substrate increased steeply as the deposition rate increases. It is well known that bombardment of highenergy secondary electrons and thermal radiations from target, the heat produced in the formation of the film etc. cause the substrate heating during sputter-deposition. ${ }^{3}$ However, precise understanding is still insufficient about the mechanism of the substrate heating in the sputter deposition of ITO film.

In this study, the mechanism of the substrate heating was investigated in the deposition of ITO thin films using a conventional magnetron sputtering system. It was found that the incidence power into the substrate during film deposition can be reduced to about $1 / 9$ by removing the high-energy electron bombardment to the substrate, and the heat of formation of the ITO film was estimated to be below $1 / 50$ of the incident power.

\section{Experimental}

A dc magnetron sputtering system shown in Fig. 1 was used. $\mathrm{In}_{2} \mathrm{O}_{3}-5$ wt. $\% \mathrm{SnO}_{2}$ sintered disk of $10 \mathrm{~cm}$ in diameter was used as the target and sputtering was performed in Ar. Typical sputtering conditions are listed in Table 1.
Figure 2 shows the incidence heating power measurement tool used in this study. The incidence power to the copper plate $(2 \mathrm{~cm} \times 2 \mathrm{~cm})$ is transferred to the copper block with a large heat capacitance through a copper column shown in the Fig. 2. The incidence power $Q$ transferred through the column can be calculated from the differences in the temperatures $\Delta \mathrm{T}$ between the positions in the copper column by the following equation, $Q=$ $\mathrm{KA} \Delta \mathrm{T} / \ell, \mathrm{K}$ : thermal conductivity of copper, $\mathrm{A}$ : the area of cross section of the copper column, $\ell$ : distance between the positions where column temperature was measured. All of the incidence power into the substrate was assumed to be transferred to the copper block, since the temperature of the copper plate was kept below $30^{\circ} \mathrm{C}$

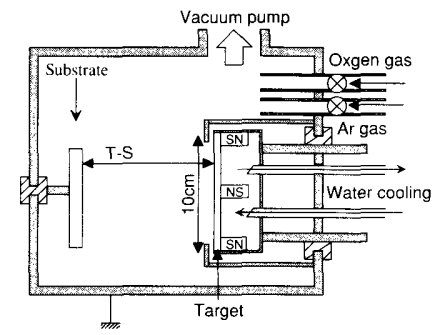

Fig. 1 Magnetron sputtering system using in this study.

Table 1 Typical sputtering conditions.

\begin{tabular}{ll}
\hline Sputtering method & $\mathrm{DC}$ magnetron sputtering \\
\hline Target & $\mathrm{In}_{2} \mathrm{O}_{3-5} \mathrm{wt} \% \mathrm{SnO}_{2}$ \\
\hline Sputtering gas flow rate & $90[\mathrm{sccm}]$ \\
\hline Sputtering gas pressure & $6[\mathrm{mTorr}]$ \\
\hline Target-substrate (T-S) distance & $5 \mathrm{~cm}, 11 \mathrm{~cm}$ \\
\hline Sputtering voltage & $\doteqdot 330 \sim 370[\mathrm{~V}]$ \\
\hline Discharge current & $\doteqdot 90 \sim 270[\mathrm{~mA}]$ \\
\hline
\end{tabular}


during the measurement, which suggests that the power loss through thermal radiation can be neglected. The mean incidence power density $\mathrm{P}$ to the substrate can be estimated from the area of copper plate $\mathrm{S}$ and $\mathrm{Q}$.

\section{Results and Discussion}

The incidence power into the substrate was measured at different target-substrate distances(T-S distance). Figure 3 shows the changes in the incidence power with sputtering power measured at T-S distances of $5 \mathrm{~cm}$ and $11 \mathrm{~cm}$. When films are deposited at a T-S distance of 5 $\mathrm{cm}$, it is evident from the Fig. 3 that the incidence power increased as the sputtering power increased and takes a value above $800 \mathrm{~mW} / \mathrm{cm}^{2}$ at the sputtering power of 100 $\mathrm{W}$. This large incidence power is the main reason for the substrate heating and induces thermal damages in the plastic film substrate when the incidence power cannot escape sufficiently to the substrate holder.

It should be also noted that the incidence power is decreased markedly by increasing the T-S distance from 5 $\mathrm{cm}$ to $11 \mathrm{~cm}$, that is, the incidence power can be reduced to about $1 / 9$ at the sputtering power of $100 \mathrm{~W}$. The deposition rate was decreased from $71.5 \mathrm{~nm} / \mathrm{min}$ to $24.7 \mathrm{~nm} /$ min by the increase in the distance. It should be noted that the decrease in the incident power is much more significant than the decrease in the deposition rate.

It is well known that bombardment of secondary electrons emitted from the target causes the substrate heating. This incidence power into substrate due to the electron bombardment can be removed completely by applying a magnetic field in the space near substrate as shown in Fig. 4(a). In order to apply a magnetic field about 300

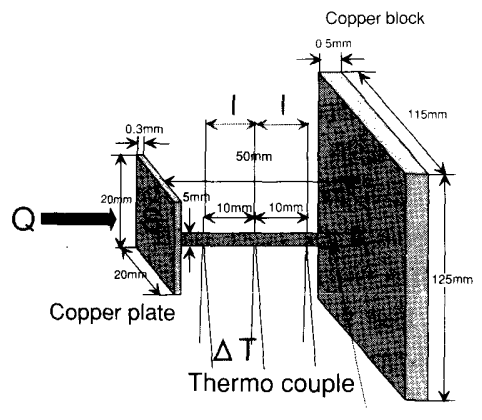

A

Fig. 2 Schematic diagram of the system used to measure the incident power into substrate.

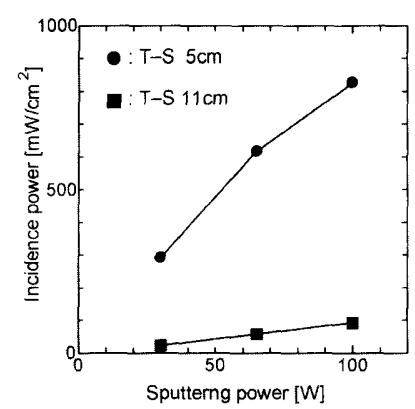

Fig. 3 Changes in the incidence power with sputtering power at different T-S distances.
Oe in front of the substrate, permanent magnet was used and arranged as shown in Fig. 4(b). By using this measurement system, the incidence power into the substrate was measured. Figure 5 shows the changes in the incidence power by the removal of the electron bombardment to the substrate. T-S distance was fixed at $5 \mathrm{~cm}$. It is clear from the figure that the incidence power can be reduced significantly to about $1 / 8$ by the removal of the electron bombardment. This suggests that the highenergy electron bombardment is the main origin of the substrate heating in the sputter-deposition using a conventional magnetron sputtering system shown in Fig. 1 . It should be noted that this removal of the electron bombardment to the substrate does not change the deposition rate as shown in Fig. 6. This indicates that the incidence power into substrate caused by the electron bombardment can be estimated from the changes in the incidence power shown in Fig. 5.

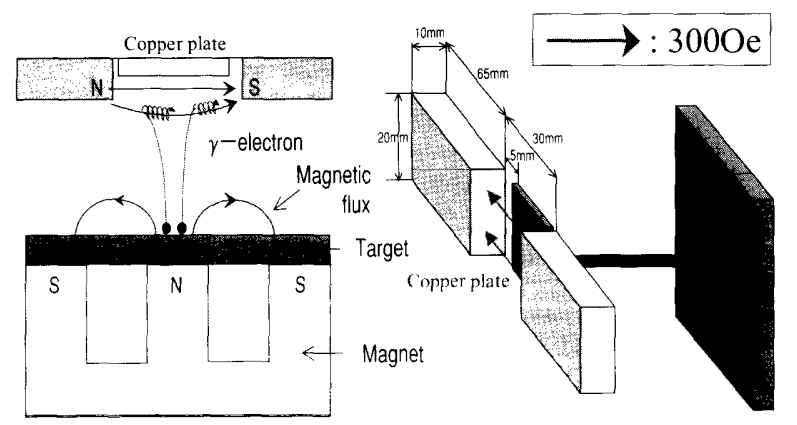

(a)

(b)

Fig. 4 Removal of the electron bombardment to the copper plate using permanent magnet.

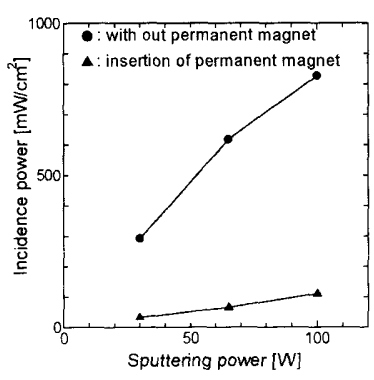

Fig. 5 Reduction in the incidence power into substrate by the removal of electron bombardment using permanent magnet at a T-S distance of $5 \mathrm{~cm}$.

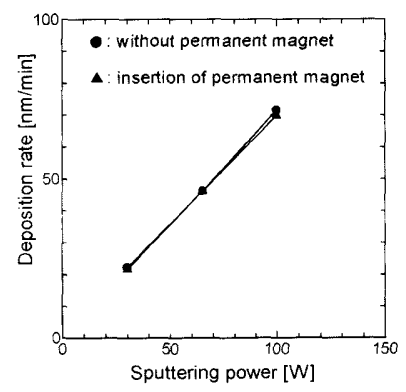

Fig. 6 Changes in the deposition rate by applying magnetic field. 


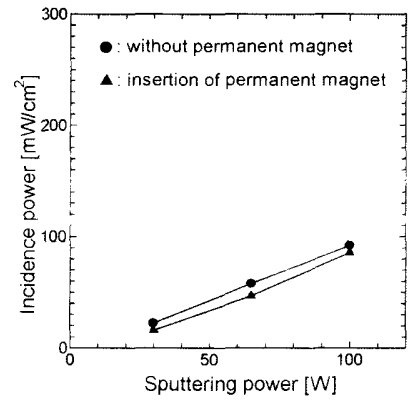

Fig. 7 Reduction in the incidence power into substrate by the removal of electron bombardment using permanent magnet at a T-S distance of $11 \mathrm{~cm}$.

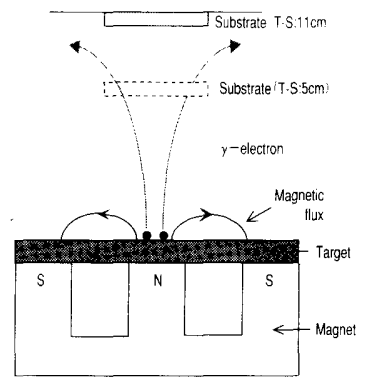

Fig. 8 Trajectory of secondary electrons emitted from the target.

The incidence power, however, was changed little by the application of magnetic field in the sputtering at T-S distance of $11 \mathrm{~cm}$ as shown in Fig. 7 . This indicates that only few electrons bombard the substrate at this T-S distance. This can be explained by the model shown in Fig. 8 , that is, trajectory of the secondary electrons emitted from the target is curved by the magnetic field of the magnetron cathode as shown in the figure, so that, the electrons emitted from the center of the target can bombard the substrate, when substrate is arranged at a T-S distance of $5 \mathrm{~cm}$. While, the secondary electrons cannot arrive at the substrate when the T-S distance is increased to $11 \mathrm{~cm}$.

The heat of formation of $\operatorname{In}_{2} \mathrm{O}_{3}$ film is another source of substrate heating during film deposition. This can be estimated from the deposition rate of the film. In order to estimate the power, following assumption was used ; all of the indium atoms and oxygen atoms are arrived at substrate with a kinetic energy of $6.7 \mathrm{eV},{ }^{4}$ and the heat of formation from indium atoms and oxygen atoms is $2160 \mathrm{~kJ} / \mathrm{mol}^{5}$.

The incidence power due to the heat of formation of the $\mathrm{In}_{2} \mathrm{O}_{3}$ film along with the incidence power caused by the high energy electron bombardment at each T-S distances are listed in Table 2. Compared with the total incidence power into substrate, the incidence power due to the heat of formation of the film was very small and estimated to be below $1 / 50$ at T-S distance of $5 \mathrm{~cm}$ and sputtering power of $100 \mathrm{~W}$. It should be noted that there are
Table 2 The incidence power into substrate caused by various origins.

\begin{tabular}{|c|c|c|}
\hline $\begin{array}{l}\text { Sputtering power : } \\
100 \mathrm{~W}\end{array}$ & $\begin{array}{l}\text { T-S distance: } \\
5 \mathrm{~cm}\end{array}$ & $\begin{array}{l}\text { T-S distance : } \\
11 \mathrm{~cm}\end{array}$ \\
\hline Deposition rate & $71.5 \mathrm{~mm}$ min & $24.7 \mathrm{~nm} \mathrm{~min}$ \\
\hline $\begin{array}{l}\text { Incidence power due to } \\
\text { electron bombardment }\end{array}$ & $\begin{array}{l}716.1 \mathrm{~mW} \mathrm{~cm}- \\
(86.6 \%)\end{array}$ & $\begin{array}{l}7.4 \mathrm{~mW} \cdot \mathrm{cm}^{2} \\
(8.0 \%)\end{array}$ \\
\hline $\begin{array}{l}\text { Incidence power due to } \\
\text { the heat of formation of } \\
\mathrm{In}_{2} \mathrm{O}_{3} \text { film }\end{array}$ & $\begin{array}{l}16 \mathrm{~mW} \mathrm{~cm} \mathrm{~cm}^{2} \\
(2.0 \%)\end{array}$ & $\begin{array}{l}5.7 \mathrm{~mW} / \mathrm{cm}^{2} \\
(6.0 \%)\end{array}$ \\
\hline $\begin{array}{l}\text { Incidence power come } \\
\text { from other origins }\end{array}$ & $\begin{array}{l}94.1 \mathrm{~mW} / \mathrm{cm}^{2} \\
(11.4 \%)\end{array}$ & $\begin{array}{l}80 \mathrm{~mW} / \mathrm{cm}^{2} \\
(86 \%)\end{array}$ \\
\hline Total incidence power & $\begin{array}{l}826.2 \mathrm{~mW} / \mathrm{cm}^{2} \\
(100 \%)\end{array}$ & $\begin{array}{l}93.1 \mathrm{~mW} / \mathrm{cm}^{2} \\
(100 \%)\end{array}$ \\
\hline
\end{tabular}

incidence powers come from other origins, such as thermal radiations from the target shield, incidence of electrons from plasma etc.

\section{Conclusion}

In this study, incidence power into substrate during film deposition was investigated in a conventional magnetron sputtering system, and following results were obtained.

1) Most of the incidence power into the substrate is originated in the bombardment of high energy electrons, and can be reduced to $1 / 9$ by removing the electron bombardment to the substrate.

2) Applying a magnetic field in the space near substrate or increasing a distance between the substrate and target cathode is effective to reduce the incidence power significantly into the substrate.

3) Compared with the total incidence power into substrate, the incidence power due to the heat of formation of the film was estimated to be below $1 / 50$.

These results indicate that substrate heating during the sputter-deposition of ITO thin films can be reduced significantly by the suppression of high energy electron bombardment to the substrate. Further reduction may be possible by the improvement of cooling system and the suppression of the incidence of electrons from the plasma.

\section{References}

1) R. H. Freiend, R. W. Gymer, B. Holmes, J. H. Burroughes, R. N. Marks, C. Taliani, D. D. C. Bradely, D. A. Dos Santos, J. L. Bredas, M. Logdlund, and R. W. Salaneck, Nature, 397, 121 (1999).

2) C. C. Wu, C. I. Wu, J. C. Sturn, and A. Kahn, Appl. Phys. Lett., 70, 1348(1997).

3) J. L. Vossen, W. Kern, Thin Film Process, Academic press, 105 (1978).

4) Y. Hoshi, E. Suzuki, and H. Shimizu, Electrochim. Acta, 44, 3933 (1999).

5) N. Suzuki, Kagaku-binran kiso- hen 2, (Ed. Nihonkagakukai), Maruzen, Chap. 7 (1993) (in Japanese). 